\title{
Impact of Culture Sensitivity Reports on the Pattern of Antibiotics use and Cost of Therapy: A Prospective Observational study
}

\author{
Ummara Altaf \\ Riphah International University - Lahore Campus \\ Muhammad Furqan Akhtar \\ Riphah International University - Lahore Campus \\ Bashir Ahmad \\ Riphah International University - Lahore Campus \\ Hassan Mehmood Yasir \\ University of the Punjab \\ Brian Godman \\ Strathclyde Institute of Pharmacy and Biomedical Sciences \\ Furqan K Hashmi \\ University of the Punjab \\ Hamid Saeed \\ University of the Punjab \\ Zikria Saleem ( $\sim$ xikria@gmail.com) \\ Universiti Sains Malaysia
}

\section{Research article}

Keywords: Anti-microbial resistance, Anti-microbial stewardship, Culture Sensitivity Reports, Cost, Definitive treatment, Empirical treatment

Posted Date: August 31st, 2020

DOI: https://doi.org/10.21203/rs.3.rs-67568/v1

License: (c) (1) This work is licensed under a Creative Commons Attribution 4.0 International License. Read Full License 


\section{Abstract}

Background: There are concerns with inappropriate prescribing of antibiotics in hospitals especially broad spectrum in Pakistan and the subsequent impact on antimicrobial resistance rates. One recognized way to reduce inappropriate prescribing is for empirical therapy to be adjusted according to the result of culture sensitivity reports.

Objective: To find the impact of culture sensitivity reports on the use of antibiotics and cost in a leading tertiary care hospital in Lahore.

Methods: This prospective observational study was carried out in Ghurki trust teaching hospital. A total of 465 positive culture patients were taken over an 8 month study period using convenient sampling techniques and immediately sent to the microbiology laboratory for pathogen identification and susceptibility testing using the Kirby-Bauer disc diffusion method. Additional data was collected from the patient medical file which included demographic data, sample type, causative microbe, anti-microbial treatment given in empirical and definitive treatment as well as medicine costs.

Results: Total of 497 isolates were detected from the 465 patient samples, which included 309 gram-negative rods and 188 gram-positive cocci. Out of 497 isolates, the most common Gram-positive pathogen isolated was MSSA (28.4\%) and Gram-negative was E. coli (23.8\%). Most of the gram-negative isolates were found to be resistant to ampicillin and co-amoxiclav. Most of the A. baumannii isolates were resistant to carbapenems. Gram-positive microorganism showed the maximum sensitivity to linezolid and vancomycin. The most widely used antibiotics in empirical therapy were cefoperazone+sulbactam, ceftriaxone, amikacin, vancomycin and metronidazole whereas high use of linezolid, clindamycin, meropenem and piperacillin + tazobactam was evidenced in definitive treatment. Empiric therapy was adjusted in 222 (71.8\%) cases of Gram-negative infections and 131 (69.6\%) cases of gram-positive infections (p-value $<0.0001)$. Compared with empirical therapy, there was a $13.8 \%$ reduction in the number of antibiotics in definitive treatment. The average costs of antibiotics in definitive treatment was less than the empirical treatment (8.2\%) and the length of hospitalization also decreased.

Conclusion: Culture sensitivity reports helped reduce antibiotic utilization, hospital stay and costs as well as helping select the most appropriate treatment. We also found an urgent need for implementing antimicrobial stewardship programs and the development of hospital antibiotic guidelines within the hospital to reduce future unnecessary prescribing of broad-spectrum antibiotics.

\section{Introduction}

The emergence of antimicrobial resistance (AMR) is a worldwide problem impacting on morbidity, mortality and costs [1-6]. Irrational use of broad-spectrum antibiotics is the most common cause of AMR [7-9]. Every year in the US, more than two million people get bacterial infections, which are mostly resistant to antibiotics that were previously considered effective for the types of bacterial infections [1], and currently approximately twenty-three thousand people die in a year in the US due to AMR [1]. There are similar figures in Europe [10]. The improved prescribing of antibiotics improves therapeutic outcomes with the minimum emergence of AMR [11-14]. However, it is well known that most of the restricted group of broad spectrum antibiotics are prescribed without proper indication potentially increasing AMR rates $[15,16]$. Effective antimicrobial therapy depends on the early identification of causative microbes through culture sensitivity testing and the appropriate selection of antibiotics according to the results $[11,17,18]$. However, due to the threat of multidrug resistant hospital-acquired infections and for the coverage of multiple microbes, typically broadspectrum are started as an empirical therapy $[11,19-21]$. In order though to reduce unnecessary use of antibiotics and 
treatment costs, as well as to avoid rising AMR rates, empirical therapy should subsequently be adjusted according to the result of culture sensitivity reports $[11,22-26]$.

Typically though, the results of blood cultures are often ignored because the patients show a therapeutic response to empiric therapy; however, this is not always the case [20,21,25]. Against this, antimicrobial stewardship programmes (ASPs) have been developed in hospitals to improve future antibiotic utilization and reduce subsequent AMR rates [16, 27-29]. As part of these activities, ASPs generally encourage the de-escalation of therapy to improve the use of antibiotics [30,31]. However to date, there is limited information regarding the extent to which culture sensitivity reports help physicians in the selection of the most appropriate antibiotic treatment especially in lower and middle income countries (LMICs) where resources are more limited [21, 32]. In one study in India, it was concluded that result of blood culture reports had a limited effect on the narrowing of antibiotics and the underutilization of culture sensitivity reports was observed in a study in England $[20,21]$ as well as Ghana where patients in the public system had to pay for sensitivity testing [33]. Choudhary et al also found that a change of therapy was only undertaken in $20.9 \%$ of positive culture patients. We are aware that there can be challenges with ordering culture reports among hospitals in LMICs with high rates of empiric prescribing [34-38]. However, we are aware that the results of culture reports can help reduce the number of antibiotics prescribed, with Berild et demonstrating a $22 \%$ reduction consumption of antibiotics with definitive treatment [25]. To the best of our knowledge though, no such study has been conducted in Pakistan to review the impact of culture sensitivity testing on antimicrobial use. This is important as there are appreciable concerns with AMR is Pakistan driven by excessive use, leading to the recent publication of a national action plan and other suggestion to address the over use of antibiotics [39-43]. Consequently, we aimed to address this by ascertaining the resistance patterns of bacterial isolates and the subsequent impact of culture sensitivity tests on the subsequent use of antibiotics as well as the cost of therapy in a leading tertiary-care hospital in Pakistan. This builds on similar activities in other LMICs [44]. We believe the findings can guide subsequent utilization of antibiotics in this leading tertiary hospital in Pakistan and wider.

\section{Methods}

\section{1. Study design and study setting}

This prospective observational study was conducted in Ghurki Trust Teaching Hospital (GTTH) between May 2018 and Dec 2018. The hospital is a charitable organization in Lahore, Pakistan, with a capacity of 600 beds. The hospital provides health care services from primary to tertiary health care. This hospital has all departments with a particular specialty in orthopedic medicine where the hospital has been awarded with the name of Center of excellence in Pakistan for arthroplasty and spinal surgery by Pakistan Orthopedic Association (POA), and POA fellows are being trained regularly in the hospital.

\subsection{Study tool}

A standardized paper data collection form was used to collect all information. The data collection form consisted of three main parts. The first part contained patient demographic data i.e. the patient's age, gender, the total length of hospitalization, ward, past surgical history and the treatment based on any biomarker data. The second part consisted of the type of the sample, causative agent, identification and the sensitivity pattern of antibiotics. The last part consisted of the brand name, generic name, route, frequency, duration, indication, treatment type and cost of the antibiotics used in empirical and in definitive therapy $[25,45]$. 


\subsection{Inclusion and exclusion criteria}

Patients with positive culture reports during the study duration were included in this study. The patients with a negative culture report and ambulatory care patients were excluded from our study because we were principally concerned with in-patient care in this study. Patients who died prior to the index of culture report or discharged earlier prior to the availability of culture reports were also be excluded. Finally, patients with medication records that had irrelevant or incomplete information were also excluded from the study.

\subsection{Data collection}

A sample was taken from the patient infectious site for pathogen identification and antibiotic sensitivity testing. The samples were immediately transferred to the microbiological laboratory and subjected to bacteriological examination. Mostly the Blood agar and MacConkey agar were used for the identification of microorganisms. The antibiotic susceptibility pattern of all the bacterial pathogens was determined by Kirby-Bauer Disc Diffusion Technique according CLSI guidelines [46]. The interpretation of the test was performed according to CLSI guidelines as sensitive and resistant. In case of positive culture reports, patients were observed for their whole length of hospital stay (from the day of positive culture report to the last day of their treatment) to determine the consumption of antibiotics, length of hospital stay, and cost of antibiotics. Susceptibility patterns of microbes were noted in order to observe the pattern of culture guided definitive therapy.

\subsection{Data Analysis}

For Antibiotic consumption, data were analyzed by using the ATC/DDD methodology established by the WHO [47]. The ATC/DDD system is a tool for measurement of drug utilization and used for comparison purposes at regional, national and international levels $[48,49]$. In the ATC classification system, medicines are classified into different groups based on the organ system upon which they act, as well as their chemical, pharmacological and therapeutic characteristics. Define Daily Dose (DDD) is a unit of measurement and it is defined as the assumed average maintenance dose per day for a drug used for its main indication in adults. Only medicines with an ATC code can have DDD values. DDD value of drugs is defined by WHO and it is updated regularly [50].

DDD of commonly used antibiotics in empirical and definitive treatment are calculated separately. The antibiotic consumption at a certain period is calculated by 100 patient admissions and for 1000 patient days to provide data for comparative purposes.

\subsection{Cost Analysis}

The cost of antibiotics used in empirical and definitive treatment were calculated by calculating the per day cost of each antibiotic and then multiplied this by the total number of days that given patients received that antibiotic. The cost savings were calculated by subtracting the cost of definitive therapy from the cost of empirical therapy. We calculated the cost in Pakistani rupees and also in US Dollar for comparison purpose.

\subsection{Ethical approval}


Ethics Approval from the hospital ethical committee was taken before starting the study (Ref No 5574). The study was performed according to the ethics standards and data were collected according to the defined time duration.

\subsection{Statistical analysis}

Statistical Process for Social Sciences (SPSS version) program was selected to analyze data obtained. Results were presented in the form of frequency, percentages, mean and standard deviation in the form of tabular and graphical representation. Chi-square test was employed by using graph pad prism 5.0 to analyze the association among variables. $\mathrm{P}<0.05$ with $95 \%$ confidence interval was considered for statistically significant results.

\section{Results}

\subsection{Demographic characteristics of selected patients}

A total of 465 patients were identified with positive culture reports. Out of these patients, 299 (64.3\%) were men and 166 (35.7\%) were women. The majority of the patients were aged between 19-40 years (38.3\%). Table 3.1 depicts the past surgical history of studied patients and it showed that majority of patients suffered from surgical site infections $(62.8 \%)$. The parenteral route of administration was very prevalent (81.2\%). Co-morbid conditions presented in majority of patients and mostly patients suffered from diabetes mellitus. The majority of the patients were admitted in the orthopaedic ward reflecting the fact that GTTH is a POA training hospital. Different samples were taken for microbiological identification and the majority of the samples were taken from pus. 
Table 3.1

Demographic data of patients

\begin{tabular}{|c|c|c|}
\hline Gender & Number & Percentage \\
\hline Male & 299 & $64.3 \%$ \\
\hline Female & 166 & $35.7 \%$ \\
\hline \multicolumn{3}{|l|}{ Age group division } \\
\hline Less than 18 year & 95 & $20.4 \%$ \\
\hline $19-40$ years & 178 & $38.3 \%$ \\
\hline $41-60$ years & 140 & $30.1 \%$ \\
\hline $61-85$ years & 52 & $11.2 \%$ \\
\hline \multicolumn{3}{|l|}{ Route of administration } \\
\hline Oral & 389 & $18.8 \%$ \\
\hline Parenteral & 1676 & $81.2 \%$ \\
\hline \multicolumn{3}{|l|}{ Prescribing Trend } \\
\hline Generic prescribing & $73 / 2060$ & $3.3 \%$ \\
\hline Brand Prescribing & $1987 / 2060$ & $96.7 \%$ \\
\hline \multicolumn{3}{|l|}{ Past surgical history } \\
\hline Yes & 292 & $62.8 \%$ \\
\hline No & 173 & $37.2 \%$ \\
\hline \multicolumn{3}{|l|}{ Treatment Based On biomarkers } \\
\hline ESR & 67 & $14.4 \%$ \\
\hline CRP & 66 & $14.1 \%$ \\
\hline \multicolumn{3}{|l|}{ Length of Hospitalization } \\
\hline Average LOH before the availability of Culture reports (days) & 12 & $60 \%$ \\
\hline Average LOH after the availability of Culture reports (days) & 8 & $40 \%$ \\
\hline \multicolumn{3}{|l|}{ Ward } \\
\hline Orthopedic & 314 & $67.5 \%$ \\
\hline ICU & 69 & $14.9 \%$ \\
\hline Medical & 34 & $7.3 \%$ \\
\hline Surgical & 28 & $6 \%$ \\
\hline Paeds & 13 & $2.8 \%$ \\
\hline Gynaecology & 7 & $1.5 \%$ \\
\hline
\end{tabular}

ESR $=$ Erythrocyte sedimentation rate, $\mathrm{CRP}=\mathrm{C}$-reactive protein, $\mathrm{LOH}=$ Length of Hospitalization, $\mathrm{ICU}=$ Intensive care unit, Others = High vaginal swab (3), Sputum (3), Cerebrospinal fluid (2). 


\begin{tabular}{|c|c|c|}
\hline Gender & Number & Percentage \\
\hline \multicolumn{3}{|l|}{ Nature of the sample } \\
\hline Pus & 230 & $49.5 \%$ \\
\hline Urine & 86 & $18.5 \%$ \\
\hline Tissue & 50 & $10.7 \%$ \\
\hline Wound Swab & 42 & $9 \%$ \\
\hline Bone & 18 & $3.9 \%$ \\
\hline Blood & 10 & $2.1 \%$ \\
\hline Sample from catherization & 21 & $4.5 \%$ \\
\hline Others & 8 & $1.6 \%$ \\
\hline \multicolumn{3}{|l|}{ Co-morbidities } \\
\hline Diabetes & 101 & $21.7 \%$ \\
\hline Hypertension & 61 & $13.11 \%$ \\
\hline Hepatitis C & 54 & $11.6 \%$ \\
\hline Tuberculosis & 14 & $3 \%$ \\
\hline Ischemic Heart Disease & 13 & $2.7 \%$ \\
\hline Quadriplegic & 12 & $2.5 \%$ \\
\hline
\end{tabular}

\subsection{Microbiological finding of positive culture reports}

A total of 497 isolates were detected from the 465 patient samples as 16 (3.4\%) patients had polymicrobes. $62.2 \%$ gram-negative rods were isolated and $37.8 \%$ were gram-positive cocci. Table 3.2 showed that among the 188 isolated gram-positive microorganism, the most common pathogen was Methicillin-sensitive Staphylococcus aureus (MSSA) 141 (28.4\%). Among the 309 isolated gram-negative microorganism, the most common pathogen was E.coli 118 (23.8\%). 
Table 3.2

Microbiological finding of positive culture reports

\begin{tabular}{|lll|}
\hline Organism & Number & Percentage \\
\hline Gram-positive bacteria & & \\
\hline Methicillin-sensitive Staphylococcus aureus & 141 & $28.4 \%$ \\
\hline Methicillin-resistant Staphylococcus aureus & 22 & $4.4 \%$ \\
\hline Streptococcus pyogenes & 12 & $2.4 \%$ \\
\hline Staphylococcus epidermidis & 8 & $1.6 \%$ \\
\hline Enterococcus faecalis & 4 & $0.8 \%$ \\
\hline Staphylococcus saprophyticus & 1 & $0.2 \%$ \\
\hline Gram-negative bacteria & & \\
\hline Escherichia coli & 118 & $23.8 \%$ \\
\hline Pseudomonas aeruginosa & 55 & $11.1 \%$ \\
\hline Klebsiella pneumoniae & 51 & $10.2 \%$ \\
\hline Acinetobacter baumannii & 39 & $7.9 \%$ \\
\hline Proteus mirabilis & 35 & $7 \%$ \\
\hline Citrobacter & 5 & $1 \%$ \\
\hline Enterobacter & 3 & $0.6 \%$ \\
\hline Salmonella typhi & $5.2 \%$ \\
\hline Serratia marcescens & 35 & \\
\hline
\end{tabular}

\subsection{Sensitivity pattern of antibiotics}

Antibiotic sensitivity testing showed that E. coli was sensitive for more than $75 \%$ cases in fosfomycin (100\%), colistin (95.8\%), polymyxin-b (93.7\%), tigecycline (92.8\%), amikacin (86\%), Imipenem (82.5\%), chloramphenicol (79.4\%) and in meropenem (78\%). P. aeruoginosa showed more than 75\% sensitivity in chloramphenicol and fosfomycin (100\%), polymyxin-b (96\%) and in colistin (95.8\%). K. pneumoniae showed more than $75 \%$ sensitivity in meropenem (80\%), imipenem (90.3\%), chloramphenicol (94.7\%) and $100 \%$ in fosfomycin, polymyxin-b, colistin and in tigecycline. $A$. baumannii showed more than $75 \%$ sensitivity in polymyxin-b and in colistin (96.2\%). P. mirabilis showed more than $75 \%$ sensitivity in meropenem (85.1\%), piperacillin+tazobactam (84\%) and 100\% in cefoperazone+sulbactam and in tigecycline.MSSA showed more than 75\% sensitivity in cefoxitin (100\%), vancomycin (100\%), linezolid (95.7\%), tigecycline (95.4\%), clindamycin (94.1\%), amikacin (90.1\%), minocycline (89.7\%), rifampicin (88.5\%), co-amoxiclav (80\%) and in gentamicin (75.9\%).Ampicillin and co-amoxiclav showed high level of resistance in Gram-negative microorganisms. Cephalosporins and fluoroquinolones also exhibited high levels of resistance in all Gram-negative microbes and even in MSSA. All the A. baumannii isolates showed high levels of resistance to all antibiotics even for carbapenems. Some resistant strains of linezolid also observed in MSSA, which is alarming and needs to be 
addressed. Overall, there are serious concerns surrounding the extent of AMR which need to be urgently addressed (Table 3.3). 
Table 3.3

Sensitivity pattern of antibiotics

\begin{tabular}{|c|c|c|c|c|c|c|}
\hline Antibiotics & $\begin{array}{l}\text { Escherichia } \\
\text { coli }\end{array}$ & $\begin{array}{l}\text { Pseudomonas } \\
\text { aeruginosa }\end{array}$ & $\begin{array}{l}\text { Klebsiella } \\
\text { pneumoniae }\end{array}$ & $\begin{array}{l}\text { Acinetobacter } \\
\text { baumannii }\end{array}$ & $\begin{array}{l}\text { Proteus } \\
\text { mirabilis }\end{array}$ & $\begin{array}{l}\text { Methicillin } \\
\text { sensitive } \\
\text { staphylococcus } \\
\text { aureus }\end{array}$ \\
\hline Ampicillin & 6/94(6.3\%) & 4/13 (30.7\%) & NA & NA & NA & $6 / 29(20.6 \%)$ \\
\hline Co-amoxiclav & $\begin{array}{l}11 / 74 \\
(14 \%)\end{array}$ & $6 / 11(54.5 \%)$ & $\begin{array}{l}9 / 34 \\
(36.4 \%)\end{array}$ & NA & $\begin{array}{l}3 / 20 \\
(15 \%)\end{array}$ & $8 / 10(80 \%)$ \\
\hline $\begin{array}{l}\text { Piperacillin } \\
+ \\
\text { Tazobactam }\end{array}$ & $\begin{array}{l}62 / 94 \\
(65.9 \%)\end{array}$ & $22 / 31(70 \%)$ & $\begin{array}{l}19 / 27 \\
(70.3 \%)\end{array}$ & 9/27 (33.3\%) & $\begin{array}{l}21 / 25 \\
(84 \%)\end{array}$ & NA \\
\hline Penicillins & NA & NA & NA & NA & NA & $24 / 113(21.1 \%)$ \\
\hline Cefepime & $\begin{array}{l}8 / 37 \\
(21.6 \%)\end{array}$ & 8/22 (36.3\%) & $\begin{array}{l}5 / 12 \\
(41.6 \%)\end{array}$ & $3 / 20(15 \%)$ & $\begin{array}{l}5 / 11 \\
(45.4 \%)\end{array}$ & NA \\
\hline Cefixime & $\begin{array}{l}2 / 44 \\
(4.5 \%)\end{array}$ & NA & $1 / 9(11.1 \%)$ & NA & NA & NA \\
\hline Cefuroxime & $\begin{array}{l}4 / 75 \\
(5.3 \%)\end{array}$ & 3/9 (33.3\%) & $2 / 28(7.1 \%)$ & NA & $\begin{array}{l}2 / 21 \\
(9.5 \%)\end{array}$ & $27 / 45(60 \%)$ \\
\hline Ceftriaxone & $\begin{array}{l}8 / 84 \\
(9.5 \%)\end{array}$ & $6 / 16(37.5 \%)$ & $\begin{array}{l}7 / 31 \\
(22.5 \%)\end{array}$ & NA & $\begin{array}{l}5 / 21 \\
(23.8 \%)\end{array}$ & $21 / 28(75 \%)$ \\
\hline Cefazolin & NA & NA & NA & NA & NA & $21 / 35(60 \%)$ \\
\hline Cefoxitin & NA & NA & NA & NA & NA & $107 / 107(100 \%)$ \\
\hline Ceftazidime & $\begin{array}{l}10 / 23 \\
(43 \%)\end{array}$ & $13 / 28(36.4 \%)$ & $9 / 20(45 \%)$ & NA & $\begin{array}{l}4 / 7 \\
(57.1 \%)\end{array}$ & NA \\
\hline $\begin{array}{l}\text { Cefoperazone } \\
+ \\
\text { Sulbactam }\end{array}$ & $\begin{array}{l}12 / 21 \\
(57.1 \%)\end{array}$ & $4 / 6(66.6 \%)$ & $3 / 6(50 \%)$ & 4/14 (28.5\%) & $\begin{array}{l}6 / 6 \\
(100 \%)\end{array}$ & NA \\
\hline Meropenem & $\begin{array}{l}78 / 100 \\
(78 \%)\end{array}$ & $18 / 34(52.9 \%)$ & 28/38 (80\%) & $9 / 32(28.1 \%)$ & $\begin{array}{l}23 / 27 \\
(85.1 \%)\end{array}$ & NA \\
\hline Imipenem & $\begin{array}{l}71 / 86 \\
(82.5 \%)\end{array}$ & $16 / 26(61.5 \%)$ & $\begin{array}{l}28 / 31 \\
(90.3 \%)\end{array}$ & 7/18 (38.8\%) & $\begin{array}{l}13 / 22 \\
(59 \%)\end{array}$ & NA \\
\hline Ertapenem & $\begin{array}{l}44 / 60 \\
(73.3 \%)\end{array}$ & $4 / 6(66.6 \%)$ & $\begin{array}{l}9 / 16 \\
(56.2 \%)\end{array}$ & $3 / 13(23.0 \%)$ & $\begin{array}{l}11 / 15 \\
(73.3 \%)\end{array}$ & NA \\
\hline Ciprofloxacin & $\begin{array}{l}15 / 64 \\
(23.4 \%)\end{array}$ & 19/32 (5.9\%) & $\begin{array}{l}11 / 26 \\
(42.3 \%)\end{array}$ & $1 / 14(7.1 \%)$ & $\begin{array}{l}10 / 21 \\
(47.6 \%)\end{array}$ & $45 / 99(44.4 \%)$ \\
\hline Norfloxacin & 9/39 (23\%) & $2 / 9(22.2 \%)$ & $1 / 5(20 \%)$ & NA & NA & $21 / 54(46.2 \%)$ \\
\hline Levofloxacin & $\begin{array}{l}21 / 69 \\
(30.4 \%)\end{array}$ & $12 / 26(46.1 \%)$ & $\begin{array}{l}9 / 24 \\
(37.5 \%)\end{array}$ & $\begin{array}{l}10 / 22 \\
(45.4 \%)\end{array}$ & $\begin{array}{l}8 / 17 \\
(47 \%)\end{array}$ & $19 / 27(70.3 \%)$ \\
\hline Erythromycin & NA & NA & NA & NA & NA & $84 / 132(63.6 \%)$ \\
\hline
\end{tabular}




\begin{tabular}{|c|c|c|c|c|c|c|}
\hline Antibiotics & $\begin{array}{l}\text { Escherichia } \\
\text { coli }\end{array}$ & $\begin{array}{l}\text { Pseudomonas } \\
\text { aeruginosa }\end{array}$ & $\begin{array}{l}\text { Klebsiella } \\
\text { pneumoniae }\end{array}$ & $\begin{array}{l}\text { Acinetobacter } \\
\text { baumannii }\end{array}$ & $\begin{array}{l}\text { Proteus } \\
\text { mirabilis }\end{array}$ & $\begin{array}{l}\text { Methicillin } \\
\text { sensitive } \\
\text { staphylococcus } \\
\text { aureus }\end{array}$ \\
\hline Clarithromycin & NA & NA & NA & NA & NA & $12 / 22(54.5 \%)$ \\
\hline Amikacin & $\begin{array}{l}80 / 93 \\
(86 \%)\end{array}$ & $26 / 35$ (74.2\%) & $28 / 40(70 \%)$ & $9 / 26(34.6 \%)$ & $\begin{array}{l}15 / 27 \\
(55.5 \%)\end{array}$ & $\begin{array}{l}101 / 112 \\
(90.1 \%)\end{array}$ \\
\hline Gentamicin & $\begin{array}{l}47 / 82 \\
(55.2 \%)\end{array}$ & $14 / 30(46.6 \%)$ & $\begin{array}{l}16 / 31 \\
(51.6 \%)\end{array}$ & $6 / 24(25 \%)$ & $\begin{array}{l}24 / 78 \\
(43.5 \%)\end{array}$ & $82 / 108(75.9 \%)$ \\
\hline Tobramycin & $\begin{array}{l}22 / 44 \\
(50 \%)\end{array}$ & $15 / 25(60 \%)$ & $3 / 9(33.3 \%)$ & 7/22 (31.8\%) & $2 / 8(25 \%)$ & $37 / 54(68.5 \%)$ \\
\hline Tetracycline & $\begin{array}{l}13 / 72 \\
(18 \%)\end{array}$ & 2/7 (28.5\%) & $\begin{array}{l}8 / 22 \\
(36.3 \%)\end{array}$ & 2/15 (13.3\%) & $\begin{array}{l}3 / 12 \\
(25 \%)\end{array}$ & $41 / 83(49.3 \%)$ \\
\hline Minocycline & $\begin{array}{l}16 / 36 \\
(44.4 \%)\end{array}$ & $6 / 8(75 \%)$ & $4 / 9(44.4 \%)$ & $\begin{array}{l}20 / 29 \\
(68.9 \%)\end{array}$ & $\begin{array}{l}2 / 8 \\
(25 \%)\end{array}$ & $35 / 39(89.7 \%)$ \\
\hline Tigecycline & $\begin{array}{l}39 / 42 \\
(92.8 \%)\end{array}$ & $3 / 5(60 \%)$ & $8 / 8(100 \%)$ & $18 / 25(72 \%)$ & $\begin{array}{l}6 / 6 \\
(100 \%)\end{array}$ & $42 / 45(95.4 \%)$ \\
\hline Co-trimoxazole & $\begin{array}{l}9 / 65 \\
(13.8 \%)\end{array}$ & $1 / 9(11.1 \%)$ & $\begin{array}{l}4 / 12 \\
(33.3 \%)\end{array}$ & NA & $\begin{array}{l}2 / 16 \\
(12.5 \%)\end{array}$ & $17 / 79$ (21.5\%) \\
\hline Clindamycin & $3 / 6(50 \%)$ & NA & NA & NA & NA & $97 / 129(75.1 \%)$ \\
\hline Chloramphenicol & $\begin{array}{l}31 / 39 \\
(79.4 \%)\end{array}$ & 9/9 (100\%) & $\begin{array}{l}18 / 19 \\
(94.7 \%)\end{array}$ & $4 / 10(40 \%)$ & $\begin{array}{l}6 / 16 \\
(37.5 \%)\end{array}$ & $81 / 86(94.1 \%)$ \\
\hline Nalidixic Acid & $\begin{array}{l}7 / 39 \\
(17.9 \%)\end{array}$ & $1 / 7(14.2 \%)$ & NA & NA & NA & NA \\
\hline Fosfomycin & $\begin{array}{l}44 / 44 \\
(100 \%)\end{array}$ & 6/6 (100\%) & $3 / 3(100 \%)$ & NA & NA & NA \\
\hline Polymyxin-b & $\begin{array}{l}45 / 48 \\
(93.7 \%)\end{array}$ & $24 / 25(96 \%)$ & $\begin{array}{l}14 / 14 \\
(100 \%)\end{array}$ & $\begin{array}{l}26 / 27 \\
(96.2 \%)\end{array}$ & $\begin{array}{l}2 / 7 \\
(28.5 \%)\end{array}$ & NA \\
\hline Colistin & $\begin{array}{l}46 / 48 \\
(95.8 \%)\end{array}$ & 23/24 (95.8\%) & $\begin{array}{l}13 / 13 \\
(100 \%)\end{array}$ & $\begin{array}{l}27 / 28 \\
(96.2 \%)\end{array}$ & $\begin{array}{l}3 / 9 \\
(33.3 \%)\end{array}$ & NA \\
\hline Vancomycin & NA & NA & NA & NA & NA & $\begin{array}{l}121 / 121 \\
(100 \%)\end{array}$ \\
\hline Teicoplanin & NA & NA & NA & NA & NA & $44 / 66(66.6 \%)$ \\
\hline Linezolid & NA & NA & NA & NA & NA & $\begin{array}{l}114 / 119 \\
(95.7 \%)\end{array}$ \\
\hline Rifampicin & NA & NA & NA & NA & NA & $54 / 61(88.5 \%)$ \\
\hline NA $=$ Not available & & & & & & \\
\hline
\end{tabular}

\subsection{Calculation of the number of DDDs for commonly used antibiotics, for 100 patient admission, for 1000 patient days}


The high use of parenteral co-amoxiclav (149.66 DDS), cefoperazone + sulbactam (1100.25 DDDs), ceftriaxone (519 DDDs), amikacin (830.59 DDDs), vancomycin (256.15 DDDs) and parenteral metronidazole (375.11 DDDs) were observed with empirical treatment. In comparison with definitive treatment, the most common antibiotics prescribed were piperacillin + tazobactam (372.53 DDDs), meropenem (260.31 DDDs), oral levofloxacin (194 DDDs), oral clindamycin (187.5 DDDs) and oral linezolid (407.68 DDDs). Compared with empirical treatment, antibiotic consumption decreased by $13.8 \%$ with definitive treatment. 
Table 3.4

Calculation of No of DDD for commonly used antibiotics, for 100 patient admission, for 1000 patient days

\begin{tabular}{|c|c|c|c|c|c|c|}
\hline \multirow[t]{2}{*}{ Antibiotics (ATC code) } & \multicolumn{2}{|l|}{ No of DDD } & \multicolumn{2}{|c|}{$\begin{array}{l}\text { For } 100 \text { Patient } \\
\text { Admission }\end{array}$} & \multicolumn{2}{|c|}{ For 1000 Patient days } \\
\hline & $\begin{array}{l}\text { Empirical } \\
\text { treatment }\end{array}$ & $\begin{array}{l}\text { Definitive } \\
\text { treatment }\end{array}$ & $\begin{array}{l}\text { Empirical } \\
\text { treatment }\end{array}$ & $\begin{array}{l}\text { Definitive } \\
\text { treatment }\end{array}$ & $\begin{array}{l}\text { Empirical } \\
\text { treatment }\end{array}$ & $\begin{array}{l}\text { Definitive } \\
\text { treatment }\end{array}$ \\
\hline $\begin{array}{l}\text { Piperacillin + tazobactam } \\
\text { (J01CR05) }\end{array}$ & 246.82 & 372.53 & 1.00 & 1.52 & 2.87 & 4.34 \\
\hline $\begin{array}{l}\text { Parenteral Amoxicillin and } \\
\text { clavulanic acid (J01CR02) }\end{array}$ & 149.66 & 37.66 & 0.61 & 0.15 & 1.74 & 0.43 \\
\hline $\begin{array}{l}\text { Oral Amoxicillin and clavulanic } \\
\text { acid (J01CR02) }\end{array}$ & 53.7 & 32 & 0.21 & 0.13 & 0.62 & 0.37 \\
\hline $\begin{array}{l}\text { Cefoperazone + sulbactam } \\
\text { (J01DD62) }\end{array}$ & 1100.25 & 349.87 & 4.49 & 1.42 & 12.83 & 4.08 \\
\hline Ceftriaxone (J01DD04) & 519 & 135 & 2.11 & 0.55 & 6.05 & 1.57 \\
\hline Meropenem (J01DH02) & 174.86 & 260.31 & 0.71 & 1.06 & 2.04 & 3.03 \\
\hline Amikacin (J01GB06) & 830.59 & 298.56 & 3.39 & 1.21 & 9.69 & 3.48 \\
\hline Vancomycin (J01XA01) & 256.15 & 137.10 & 1.04 & 0.55 & 2.98 & 1.59 \\
\hline $\begin{array}{l}\text { Parenteral Ciprofloxacin } \\
\text { (J01MA02) }\end{array}$ & 138 & 116.63 & 0.56 & 0.47 & 1.60 & 1.36 \\
\hline Oral Ciprofloxacin (J01MA02) & 359 & 344.75 & 1.46 & 1.40 & 4.18 & 4.02 \\
\hline $\begin{array}{l}\text { Parenteral Moxifloxacin } \\
\text { (J01MA14) }\end{array}$ & 132 & 70 & 0.53 & 0.28 & 1.53 & 0.81 \\
\hline Oral Moxifloxacin (J01MA14) & 20 & 10 & 0.08 & 0.04 & 0.23 & 0.11 \\
\hline $\begin{array}{l}\text { Parenteral Levofloxacin } \\
\text { (J01MA12) }\end{array}$ & 66.5 & 106.83 & 0.27 & 0.43 & 0.77 & 1.24 \\
\hline Oral Levofloxacin (J01MA12) & 96 & 194 & 0.39 & 0.79 & 1.11 & 2.26 \\
\hline Tigecycline (J01AA12) & 29 & 140 & 0.11 & 0.57 & 0.33 & 1.63 \\
\hline $\begin{array}{l}\text { Parenteral Clindamycin } \\
\text { (J01FF01) }\end{array}$ & 95.33 & 80.33 & 0.38 & 0.32 & 1.11 & 0.93 \\
\hline $\begin{array}{l}\text { Oral Clindamycin } \\
\text { (J01FF01) }\end{array}$ & 17.75 & 187.5 & 0.07 & 0.76 & 0.20 & 2.18 \\
\hline $\begin{array}{l}\text { Parenteral Metronidazole } \\
\text { (J01XD01) }\end{array}$ & 375.11 & 147.10 & 1.53 & 0.60 & 4.37 & 1.71 \\
\hline Oral Metronidazole (P01AB01) & 12.4 & 23.4 & 0.05 & 0.09 & 0.14 & 0.27 \\
\hline $\begin{array}{l}\text { Parenteral Linezolid } \\
\text { (J01XX08) }\end{array}$ & 56.05 & 129.62 & 0.22 & 0.52 & 0.65 & 1.51 \\
\hline
\end{tabular}

DDD = Define Daily Dose, ATC $=$ Anatomical Therapeutic Chemical Classification System of the World Health Organization 


\begin{tabular}{|lllllll|}
\hline Antibiotics (ATC code) & No of DDD & \multicolumn{3}{l|}{$\begin{array}{l}\text { For 100 Patient } \\
\text { Admission }\end{array}$} & \multicolumn{2}{c|}{ For 1000 Patient days } \\
\hline Oral Linezolid (J01XX08) & 60.53 & 407.68 & 0.24 & 1.66 & 0.70 & 4.75 \\
\hline Colistin (J01XB01) & 0.88 & 23 & 0.003 & 0.09 & 0.01 & 0.26 \\
\hline $\begin{array}{l}\text { DDD = Define Daily Dose, ATC = Anatomical Therapeutic Chemical Classification System of the World Health } \\
\text { Organization }\end{array}$
\end{tabular}

\subsection{Cost Analysis}

The average per day cost of the antibiotics used in definitive treatment was $8.2 \%$ less than that with empiric treatment. The total average duration of patient hospitalization was 20 days, and the average duration after the availability of culture sensitivity reports was 8 days. This showed that the culture sensitivity reports helped in the reduction of the total length of hospitalization and ultimately reduced the overall costs related to the treatment of patients into his hospital. We calculated the cost in Pakistani rupees and also in US dollars for comparison purpose as shown in Table 3.5 .

Table 3.5

Cost

\begin{tabular}{|llll|}
\hline Variables & $\begin{array}{l}\text { Before the Availability of } \\
\text { Culture Report (A) }\end{array}$ & $\begin{array}{l}\text { After the Availability of } \\
\text { Culture Report (B) }\end{array}$ & $\begin{array}{l}\text { Difference } \\
\text { in cost } \\
\text { (A-B) }\end{array}$ \\
\hline $\begin{array}{l}\text { Per Day Average Cost of Antibiotics } \\
\text { (In Pakistani Rupees) }\end{array}$ & PKR $=9,225$ & PKR $=8,467$ & $\begin{array}{l}\text { PKR }=758 \\
(8.2 \%)\end{array}$ \\
\hline $\begin{array}{l}\text { Per Day Average Cost of Antibiotics ( } \\
\text { In US Dollar) }\end{array}$ & $60 \$$ & $55 \$$ & $5 \$$ \\
\hline PKR = Pakistan rupees & & & \\
\hline
\end{tabular}

\subsection{Adjustment of empirical therapy after the availability of culture sensitivity reports}

At the time of culture report, empiric therapy was given to $93.1 \%$ patients. The antibiotics administered were subsequently adjusted in 222 (71.8\%) cases of Gram-negative microorganism followed by 131 (69.6\%) in Grampositive microorganism following the results of culture sensitivity test ( $p$-value $<0.0001)$. The rates of the adjustment of antibiotics after the availability of culture reports are given in Fig 1.

\section{Discussion}

In our current study, most common microorganism isolated from the patient's sample was gram-positive MSSA, with similar results seen in other studies [20,21,51]. However, in other studies, gram negative bacteria appear more common that gram-positive bacteria [32]. This may well reflect different bacteria seen in different hospital care settings with different patient populations. In our study, most of the patients were suffering from bone diseases and 
mostly MSSA or gram-positive bacteria were involved in osteomyelitis and in bone infections [52]. The second most common bacteria found in our study was E. coli, similar to another study conducted in a tertiary care hospital in India [20] but different from another study conducted in England [21].

A high proportion of patients in our study received antibiotics before the availability of culture results, similar to other studies [53]. However, different to a recent study in South Africa where $83 \%$ of antibiotics were modified following sensitivity reports [54]. Consequently, prescribing behavior may be due to a desire to prevent patients getting severe infections without waiting for sensitivity reports. However, the empiric therapy can subsequently be adjusted according to the culture sensitivity reports to help reduce unnecessary prescribing of particularly broad spectrum antibiotics and associated costs. The most commonly used antibiotics for empiric treatment in our study were cefoperazone + sulbactam followed by amikacin. This is in contrast with the high use of piperacillin+tazobactam and meropenem as empiric therapy in other studies [20], as well as the high use of ceftriaxone in the recent point prevalence study in Pakistan [55]. This may be due to the ready availability of cefoperazone + sulbactam in GTTH and less resistance against microbes, and the use of amikacin may be due to the high prevalence of E. coli with amikacin have good therapeutic coverage against E. coli. However, this needs further analysis. We are aware that the main reasons for selecting antibiotics for empiric treatment needs to be investigated further to improve future antimicrobial use in this and other hospitals in Pakistan [56].

For definitive treatment, the most common antibiotic prescribed was linezolid, which contrasts with meropenem in another published study [20]. This may well be due to the high prevalence of MSSA in our study and that linezolid is seen to have good coverage against MSSA. However, again this needs further investigation [56]. In this study, the highest use of antibiotics was seen in ICU which was similar to the results observed in Kenya and Switzerland [35, 57], with high rates of antibiotic use in ICUs seen in the recent PPS study in Pakistan [37]. Overall, the extensive use of broad-spectrum antibiotics in definitive treatment could be explained by high bacterial resistance rates [58]. Antibiotic resistance may be reversed if the over-use of antibiotics among hospitals in Pakistan can be decreased.

Encouragingly in our study, empiric therapy was adjusted in $68.9 \%$ of the patients greater than the study conducted by Chuodhary et al (47.27\%) [20]; however, this is less than the study conducted by Berild et al (88\%) [25]. Adjustments were mostly undertaken in gram-negative microorganism compared with gram-positive microorganism similar to the study by Berild et.al [25]. We do not know why the results of culture reports were ignored by some physicians in our study. This may be because physicians mostly rely on the apparent clinical situation of the patient rather than the result of culture reports [32]. However, this will be investigated further in future studies as this is a concern.

In our study, it was observed that no national or international guidelines were available in hospital to guide empiric therapy [59]. This again needs to be urgently addressed as the high use of unnecessary antibiotics increases AMR rates [60], with adherence to guidance known to improve future antibiotic use and is increasingly considered as a robust measure of the quality of prescribing [13, 38, 61-64]. Our results suggest the urgent need to develop guidelines as well as instigate antimicrobial stewardship programmes (ASPs) in this hospital to reduce the unnecessary use of antibiotics [65]. This also applies to other hospitals in Pakistan to help improve future antimicrobial prescribing in hospitals [66].

Another major concern in our study was the high use of parenteral antibiotics (81.8\%) similar to other studies [67]. High use of parenteral antibiotics may well reflect physician and patients' views that the IV route is more effective compared with the oral route [68]. Whilst the parenteral route was more preferable in critically ill patients such as ICU patients where patients are often unable to take oral medicines, or in life threatening indication where no oral equivalent is available [68], the oral route is generally preferable where possible as it reduces the risk of cannula related infection and thrombophlebitis as well as reducing length of stay and ultimately the overall cost of treatment [62,68- 
72]. This is helped by the fact that many antibiotics are now available for switching as they have more than $90 \%$ bioavailability in their oral form. These include linezolid, fluoroquinolones, doxycycline, metronidazole and rifampicin [68].

The consumption of antibiotics decreased by $13.8 \%$ with definitive treatment compared with empirical treatment, similar to findings of Berild et al [73]. Encouragingly as well, the cost of antibiotics used in definitive therapy was $8.2 \%$ less than empiric therapy, agin similar to findings of Berild et al [25]. The true cost savings may well be higher as the early availability of culture sensitivity reports decreased the length of stay, which would ultimately decrease overall cost of patient care similar to the findings of Stevenson et al in 2012 [74].

It was also encouraging to see that only $3.3 \%$ of the antibiotics were prescribed by their brand name as generic medicines tend to be considerably less expensive [75-78]. The rates of INN prescribing in this hospital are considerably less than seen in studies conducted in Karachi (12.26\%), Hyderabad (12\%), Bangladesh (78\%) and in Islamabad (23\%) [79-82]. Higher rates can be achieved through more stringent bioequivalent studies given some of the concerns as well as generally encouraging INN names to be taught in medical and pharmacy schools similar to the UK and continued post qualification [83-86].

In this study, the most common gram-negative microbe was E. coli. Encouragingly, antibiotic sensitivity test showed that E. coli showed maximum (more than 75\%) sensitivity to fosfomycin (100\%), colistin (95.8\%), polymyxin-b (93.7\%), tigecycline \& nitrofurantoin (92.8\%), amikacin (86\%), imipenem (82.5\%), erythromycin (80\%), chloramphenicol (79.4\%) and meropenem (78\%). However, Nirangan et al (2014) showed a maximum sensitivity of imipenem (98.9\%), amikacin (82.6\%), nitrofurantoin (82.1\%), and Piperacillin + tazobactam (78.2\%) for E. coli [87] and Gales et al showed a maximum sensitivity to aztreonam (78.8\%), cefoxitin (85.8\%), ceftriaxone (75.3\%), ceftazidime (82.1\%), cefepime (84.1\%), gentamicin (81.2\%), tobramycin (75.7\%) and more than $90 \%$ in piperacillin+tazobactam (90.5\%), imipenem (99.6\%), meropenem (99.9\%), amikacin (98.6\%) and colistin (99.8\%) for E. coli [88]. We will be monitoring this closely in the future to help further guide antibiotic choices.

The most common gram-positive microbe was MSSA with antibiotic sensitivity testing showed that MSSA had maximum (more than 75\%) sensitivity to cefoxitin (100\%), vancomycin (100\%), linezolid (95.7\%), tigecycline (95.4\%), chloramphenicol (94.1\%), amikacin (90.1\%), minocycline (89.7\%), rifampicin (88.5\%), gentamicin (75.9\%), clindamycin (75.1\%) and ceftriaxone (75\%). However, Mir et al (2016) showed a maximum sensitivity of vancomycin, linezolid, rifampicin, chloramphenicol, clindamycin, amikacin, fusidic acid and gentamicin in the case of MSSA i.e. 100\%, $98.9 \%$, $95.7 \%, 94.7 \%, 86.2 \%, 84 \%, 83 \%$ and $76.6 \%$ respectively [89]. Our findings are a concern especially with some strains of MSSA showing resistance to linezolid which may well be due to the overuse of linezolid, and we will also be investigating this further.

We are aware of a number of limitations with this study. Firstly, no standard antibiotic guidelines were available for the selection of appropriate empiric and definitive therapy in he hospital. Consequently, it was impossible to determine physician adherence with hospital guidelines. Nonetheless, we believe this study was the first step to identifying the prescribing pattern of physicians after the availability of culture sensitivity reports. Secondly, our study was an observational study; consequently, we did not interfere with physician prescribing trends in the selection of antibiotic treatment. However, in the future, the impact of the involvement of a pharmacist or other key stakeholders actively involved in guiding antibiotic selection in hospitals will be investigated. Lastly, to the best of present knowledge, we believe no such research has been undertaken to date in Pakistan with a special focus on culture sensitivity reports; consequently, we were unable to compare our results with any existing studies in Pakistan. 
In spite of these limitation, we believe our findings are robust with this study highlighting the impact of culture sensitivity reports on the antibiotic use as well as the significance of culture guided therapy on definitive versus empiric treatment in Pakistan. In addition, this study highlighted the need for antibiotic guidelines for the selection of appropriate antibiotics in empiric and in definite treatment which will be helped by the instigation of ASPs in this hospital and wider.

\section{Conclusions}

Overall, culture sensitivity reports helped reduce antibiotic utilization in this hospital, decreasing hospital stay and reducing the costs of the antibiotics prescribed. However, there were concerns at the high rates of antimicrobial resistance patterns observed. Consequently, there is an urgent need for the implementation of ASPs and the development of hospital antibiotic guidelines in this hospital, and potentially wider in Pakistan, to reduce unnecessary prescribing of broad-spectrum antibiotics and improve the rationality of antibiotics through culture sensitivity reports. We will be monitoring these developments in the future.

\section{Declarations}

\section{Ethics approval and consent to participate}

The study was approved and registered from Ethics committee on human research, University College of Pharmacy, University of the Punjab, Lahore, Pakistan under the registration number (HEC/1000/PUCP/1925I). Because the manuscript does not contain any individual person's data in any form (including any individual details, images or videos), so the ethics committee has granted an exemption from requiring consent to participate. The head of departments of various wards and their staff physicians and nurses were informed about the study and they allowed the principal investigators to conduct the study in respective wards.

\section{Consent for publication}

Not applicable.

\section{Availability of data and materials}

The datasets used and/or analyzed during the current study are available from the corresponding author on reasonable request.

\section{Competing Interest}

The authors declare that they have no competing interests.

\section{Funding}

Not applicable

\section{Contributions of Authors}


Ummara Altaf is the leader of project. She facilitated the launch and smooth running of project by coordinating among all partners. Zikria prepared the detailed work plan, monitoring and evaluation system. The compilation and interpretation of factual materials of the research paper was done by Furqan K Hashmi, Hamid Saeed and Brian Godman. Ummara and Hassan Mehmood Yasir collected data. Bashir Ahmed and Muhammad Furqan Akhtar supervised and helped in the analysis of the results. Brian Godman reviewed the paper and approved the paper

\section{Acknowledgments}

This study would not have been possible without the contribution and involvement of administration and staff of GTTH hospital. Their cooperation is thankfully appreciated.

\section{References}

1. Ventola CL. The antibiotic resistance crisis: part 1: causes and threats. Pharmacy therapeutics. 2015;40(4):277.

2. Jinks T, Lee N, Sharland M, Rex J, Gertler N, Diver M, Jones I, Jones K, Mathewson S, Chiara F. A time for action: antimicrobial resistance needs global response. Bull World Health Organ. 2016;94(8):558-8A.

3. Founou RC, Founou LL, Essack SY: Clinical and economic impact of antibiotic resistance in developing countries: A systematic review and meta-analysis. PloS one 2017, 12(12):e0189621.

4. Essack SY, Desta AT, Abotsi RE, Agoba EE. Antimicrobial resistance in the WHO African region: current status and roadmap for action. J Public Health. 2017;39(1):8-13.

5. World Health Organisation. Antimicrobial resistance. 2018. Available at URL: http://www.who.int/news-room/factsheets/detail/antimicrobial-resistance.

6. Hofer U. The cost of antimicrobial resistance. Nature reviews Microbiology. 2019;17(1):3.

7. Costelloe C, Metcalfe C, Lovering A, Mant D, Hay AD. Effect of antibiotic prescribing in primary care on antimicrobial resistance in individual patients: systematic review and meta-analysis. Bmj. 2010;340:c2096.

8. Llor C, Bjerrum L. Antimicrobial resistance: risk associated with antibiotic overuse and initiatives to reduce the problem. Therapeutic advances in drug safety. 2014;5(6):229-41.

9. Bell BG, Schellevis F, Stobberingh E, Goossens H, Pringle M. A systematic review and meta-analysis of the effects of antibiotic consumption on antibiotic resistance. BMC Infect Dis. 2014;14:13-3.

10. Cassini A, Högberg LD, Plachouras D, Quattrocchi A, Hoxha A, Simonsen GS, Colomb-Cotinat M, Kretzschmar ME, Devleesschauwer B, Cecchini M. Attributable deaths and disability-adjusted life-years caused by infections with antibiotic-resistant bacteria in the EU and the European Economic Area in 2015: a population-level modelling analysis. Lancet Infect Dis. 2019;19(1):56-66.

11. Coupat C, Pradier C, Degand N, Hofliger P, Pulcini C. Selective reporting of antibiotic susceptibility data improves the appropriateness of intended antibiotic prescriptions in urinary tract infections: a case-vignette randomised study. European journal of clinical microbiology infectious diseases. 2013;32(5):627-36.

12. Ayukekbong JA, Ntemgwa M, Atabe AN. The threat of antimicrobial resistance in developing countries: causes and control strategies. Antimicrobial Resistance Infection Control. 2017;6(1):47.

13. Wathne JS, Harthug S, Kleppe LKS, Blix HS, Nilsen RM, Charani E, Smith I. The association between adherence to national antibiotic guidelines and mortality, readmission and length of stay in hospital inpatients: results from a Norwegian multicentre, observational cohort study. Antimicrobial Resistance Infection Control. 2019;8(1):63.

14. Davey P, Marwick CA, Scott CL, Charani E, McNeil K, Brown E, Gould IM, Ramsay CR, Michie S. Interventions to improve antibiotic prescribing practices for hospital inpatients. Cochrane Database Syst Rev. 2017;2:Cd003543. 
15. Hecker MT, Aron DC, Patel NP, Lehmann MK, Donskey CJ. Unnecessary use of antimicrobials in hospitalized patients: current patterns of misuse with an emphasis on the antianaerobic spectrum of activity. Arch Intern Med. 2003;163(8):972-8.

16. Mettler J, Simcock M, Sendi P, Widmer AF, Bingisser R, Battegay M, Fluckiger U, Bassetti S. Empirical use of antibiotics and adjustment of empirical antibiotic therapies in a university hospital: a prospective observational study. BMC Infect Dis. 2007;7(1):21.

17. Michel F, Franceschini B, Berger P, Arnal J-M, Gainnier M, Sainty J-M, Papazian L. Early antibiotic treatment for BAL-confirmed ventilator-associated pneumonia. Chest. 2005;127(2):589-97.

18. Raja SA, Ashraf M, Raja SA, Anjum AA, Mubarak N, ljaz T. Evaluation of Empirical Therapy in Ventilator Associated Pneumonia in ICU in a tertiary care hospital. INTERNATIONAL JOURNAL OF ADVANCED BIOTECHNOLOGY AND RESEARCH. 2019;10(1):85-93.

19. Hanon Fo -X, Sørensen TL, Mølbak K, Schønheyder H, Monnet DL, Pedersen G. Survival of patients with bacteraemia in relation to initial empirical antimicrobial treatment. Scand J Infect Dis. 2002;34(7):520-8.

20. Choudhary S, Yadav AK, Sharma S, Pichholiya M, Sharma P. Effect of blood culture reports on antibiotics use by physicians in septic patients of intensive care unit. International Journal of Research in Medical Sciences. 2017;3(9):2425-8.

21. Arbo MD, Snydman DR. Influence of blood culture results on antibiotic choice in the treatment of bacteremia. Arch Intern Med. 1994;154(23):2641-5.

22. Kim JW, Chung J, Choi S-H, Jang HJ, Hong S-B, Lim C-M, Koh Y. Early use of imipenem/cilastatin and vancomycin followed by de-escalation versus conventional antimicrobials without de-escalation for patients with hospitalacquired pneumonia in a medical ICU: a randomized clinical trial. Crit Care. 2012;16(1):R28.

23. Perez KK, Olsen RJ, Musick WL, Cernoch PL, Davis JR, Land GA, Peterson LE, Musser JM. Integrating rapid pathogen identification and antimicrobial stewardship significantly decreases hospital costs. Arch Pathol Lab Med. 2012;137(9):1247-54.

24. Garnacho-Montero J, Gutiérrez-Pizarraya A, Escoresca-Ortega A, Corcia-Palomo Y, Fernández-Delgado E, HerreraMelero I, Ortiz-Leyba C, Marquez-Vacaro J. De-escalation of empirical therapy is associated with lower mortality in patients with severe sepsis and septic shock. Intensive care medicine. 2014;40(1):32-40.

25. Berild D, Mohseni A, Diep LM, Jensenius M, Ringertz SH. Adjustment of antibiotic treatment according to the results of blood cultures leads to decreased antibiotic use and costs. J Antimicrob Chemother. 2005;57(2):32630.

26. Morency-Potvin P, Schwartz DN, Weinstein RA. Antimicrobial Stewardship: How the Microbiology Laboratory Can Right the Ship. Clin Microbiol Rev. 2017;30(1):381-407.

27. Brink AJ, Messina AP, Feldman C, Richards GA, Becker PJ, Goff DA, Bauer KA, Nathwani D, Van den Bergh D, Alliance NASS. Antimicrobial stewardship across 47 South African hospitals: an implementation study. Lancet Infect Dis. 2016;16(9):1017-25.

28. Yeo JM. Antimicrobial stewardship: Improving antibiotic prescribing practice in a respiratory ward. BMJ Open Quality. 2016;5(1):u206491. w203570.

29. Nathwani D, Varghese D, Stephens J, Ansari W, Martin S, Charbonneau C. Value of hospital antimicrobial stewardship programs [ASPs]: a systematic review. Antimicrobial Resistance Infection Control. 2019;8(1):35.

30. Davey P, Brown E, Charani E, Fenelon L, Gould IM, Holmes A, Ramsay CR, Wiffen PJ, Wilcox M. Interventions to improve antibiotic prescribing practices for hospital inpatients. Cochrane Database of Systematic Reviews 2013(4). 
31. Kaki R, Elligsen M, Walker S, Simor A, Palmay L, Daneman N. Impact of antimicrobial stewardship in critical care: a systematic review. J Antimicrob Chemother. 2011;66(6):1223-30.

32. Panaligan M, Magtolis LGV, Peña AC. Influence of blood culture and sensitivity results on the antibiotic choices of attending physicians in the management of bacteremia. Phil J Microbiol Infect Dis 1995.

33. AFRIYIE, DK, SEFAH IA, SNEDDON J, MALCOM W, McKinney R, COOPER L et al. Antimicrobial Point Prevalence Surveys in two Ghanaian hospitals: opportunities for antimicrobial stewardship. JAC Antimicrob Resist. 2020: 19.

34. Anand Paramadhas BD, Tiroyakgosi C, Mpinda-Joseph P, Morokotso M, Matome M, Sinkala F, Gaolebe M, Malone B, Molosiwa E, Shanmugam MG. Point prevalence study of antimicrobial use among hospitals across Botswana; findings and implications. Expert review of anti-infective therapy. 2019;17(7):535-46.

35. Okoth C, Opanga S, Okalebo F, Oluka M, Baker Kurdi A, Godman B. Point prevalence survey of antibiotic use and resistance at a referral hospital in Kenya: findings and implications. Hospital practice. 2018;46(3):128-36.

36. Momanya L, Oluka M, Opanga S, Nyamu D, Kurdi A, Godman B: Antibiotic prescribing patterns at a referral hospital in Kenya: a point prevalence survey. In: 4th Training Workshop and Symposium MURIA Group: 2018; 2018.

37. Saleem Z, Hassali MA, Versporten A, Godman B, Hashmi FK, Goossens H, Saleem F. A multicenter point prevalence survey of antibiotic use in Punjab, Pakistan: findings and implications. Expert review of anti-infective therapy. 2019;17(4):285-93.

38. Afriyie DK, Sefah IA, Sneddon J, MALCOM W, McKinney R, Cooper L, Kurdi A, Godman B, Seaton RA: Antimicrobial point prevalence surveys in two Ghanaian hospitals: opportunities for antimicrobial stewardship. JACAntimicrobial Resistance 2019.

39. Saleem Z, Hassali MA. Travellers take heed: Outbreak of extensively drug resistant (XDR) typhoid fever in Pakistan and a warning from the US CDC. Travel Med Infect Dis. 2019;27:127.

40. Saleem Z, Hassali MA, Versporten A, Godman B, Hashmi FK, Goossens H, Saleem F. A multicenter point prevalence survey of antibiotic use in Punjab, Pakistan: findings and implications. Expert review of anti-infective therapy. 2019;17(4):285-93.

41. Saleem Z, Hassali MA, Hashmi FK. Pakistan's national action plan for antimicrobial resistance: translating ideas into reality. The Lancet Infectious diseases. 2018;18(10):1066-7.

42. Hayat K, Rosenthal M, Gillani AH, Zhai P, Aziz MM, Ji W, Chang J, Hu H, Fang Y. Perspective of Pakistani Physicians towards Hospital Antimicrobial Stewardship Programs: A Multisite Exploratory Qualitative Study. Int J Environ Res Public Health 2019, 16(9).

43. Hayat K, Rosenthal M, Gillani AH, Chang J, Ji W, Yang C, Jiang M, Zhao M, Fang Y. Perspective of Key Healthcare Professionals on Antimicrobial Resistance and Stewardship Programs: A Multicenter Cross-Sectional Study From Pakistan. Frontiers in pharmacology 2020, 10(1520).

44. Kalaba M, Kosutic J, Godman B, Radonjic V, Vujic A, Jankovic S, Srebro D, Kalaba Z, Stojanovic R, Prostran M. Experience with developing antibiotic stewardship programs in Serbia: potential model for other Balkan countries? Journal of comparative effectiveness research. 2018;7(3):247-58.

45. Keegan MT, Gajic O, Afessa B. Severity of illness scoring systems in the intensive care unit. Critical care medicine. 2011;39(1):163-9.

46. Chitemerere TA, Mukanganyama S. In vitro antibacterial activity of selected medicinal plants from Zimbabwe. The African Journal of Plant Science Biotechnology. 2011;5(1):1-7. 
47. Sözen H, Gönen I, Sözen A, Kutlucan A, Kalemci S. Sahan MJAocm, antimicrobials: Application of ATC/DDD methodology to eveluate of antibiotic use in a general hospital in Turkey. 2013, 12(1):23.

48. Robertson J, Iwamoto K, Hoxha I, Ghazaryan L, Abilova V, Cvijanovic A, Pyshnik H, Darakhvelidze M, Makalkina L, Jakupi A, et al: Antimicrobial Medicines Consumption in Eastern Europeand Central Asia - An Updated CrossNational Study and Assessment of QuantitativeMetrics for Policy Action. Frontiers in pharmacology 2019, 9(1156).

49. Farooqui HH, Selvaraj S, Mehta A, Heymann DL. Community level antibiotic utilization in India and its comparison vis-à-vis European countries: Evidence from pharmaceutical sales data. PloS one. 2018;13(10):e0204805-5.

50. WHO. Collaborating Centre for Drug Statistics Methodology. ATC/ DDD Index. Available at URL: https://www.whocc.no/.

51. Kalaba M, Kosutic J, Godman B, Radonjic V, Vujic A, Jankovic S, Srebro D, Kalaba Z, Stojanovic R, Prostran M. Experience with developing antibiotic stewardship programs in Serbia: potential model for other Balkan countries? Journal of comparative effectiveness research. 2018;7(3):247-58.

52. Lina G, Piémont Y, Godail-Gamot F, Bes M, Peter M-O, Gauduchon V, Vandenesch F, Etienne J. Involvement of Panton-Valentine leukocidin-producing Staphylococcus aureus in primary skin infections and pneumonia. Clinical infectious diseases. 1999;29(5):1128-32.

53. Al Shimemeri A, Al Ghadeer H, Memish Z. Antibiotic utilization pattern in a general medical ward of a tertiary medical center in Saudi Arabia. Avicenna journal of medicine. 2011;1(1):8.

54. Dlamini NN, Meyer JC, Kruger D, Kurdi A, Godman B, Schellack N. Feasibility of using point prevalence surveys to assess antimicrobial utilisation in public hospitals in South Africa: a pilot study and implications. Hospital practice. 2019;47(2):88-95.

55. Saleem Z, Hassali MA, Versporten A, Godman B. A multicenter point prevalence survey of antibiotic use in Punjab, Pakistan: findings and implications. Expert Rev Anti Infect Ther. 2019;17(4):285-93.

\section{Doherty GM. Current surgical diagnosis \& treatment.}

57. Loeffler JM, Garbino J, Lew D, Harbarth S, Rohner P. Antibiotic consumption, bacterial resistance and their correlation in a Swiss university hospital and its adult intensive care units. Scand J Infect Dis. 2003;35(1112):843-50.

58. Jabeen K, Zafar A, Hasan R. Frequency and sensitivity pattern of extended spectrum beta lactamase producing isolates in a tertiary care hospital laboratory of Pakistan. Journal of Pakistan Medical Association. 2005;55(10):436.

59. Khan EA. An urgent need for National Action Plan for Infection Control and Antibiotic Stewardship in Pakistan. Clin Infect Dis. 2007;44:159-77.

60. Bin YB, Rozina A, Junaid M, Saima K, Farhan N, Maham T. A Study of Unnecessary Use of Antibiotics at a Tertiary care hospital: Urgent need to implement antimicrobial stewardship programs. J Young Pharm. 2015;7(4):311-9.

61. Nakwatumbah S, Kibuule D, Godman B, Haakuria V, Kalemeera F, Baker A, Mubita M. Compliance to guidelines for the prescribing of antibiotics in acute infections at Namibia's national referral hospital: a pilot study and the implications. Expert review of anti-infective therapy. 2017;15(7):713-21.

62. Versporten A, Zarb P, Caniaux I, Gros MF, Drapier N, Miller M, Jarlier V, Nathwani D, Goossens H. Antimicrobial consumption and resistance in adult hospital inpatients in 53 countries: results of an internet-based global point prevalence survey. The Lancet Global health. 2018;6(6):e619-29.

63. Niaz Q, Godman B, Campbell S, Kibuule D. Compliance to prescribing guidelines among public health care facilities in Namibia; findings and implications. International journal of clinical pharmacy 2020.

Page $21 / 24$ 
64. Olaru ID, Meierkord A, Godman B, Ngwenya C, Fitzgerald F, Dondo V, Ferrand RA, Kranzer K. Assessment of antimicrobial use and prescribing practices among pediatric inpatients in Zimbabwe. Journal of chemotherapy (Florence, Italy) 2020:1-4.

65. Sviestina I, Aston J, Lorrot M, Mozgis D. A comparison of antibiotic use in three specialist paediatric hospitals in France, Latvia and the UK. Eur J Hosp Pharm. 2015;22(3):132-7.

66. Saleem Z, Hassali MA, Hashmi FK, Godman B, Ahmed Z. Snapshot of antimicrobial stewardship programs in the hospitals of Pakistan: findings and implications. Heliyon. 2019;5(7):e02159.

67. James R, Upjohn L, Cotta M, Luu S, Marshall C, Buising K, Thursky K. Measuring antimicrobial prescribing quality in Australian hospitals: development and evaluation of a national antimicrobial prescribing survey tool. J Antimicrob Chemother. 2015;70(6):1912-8.

68. Cyriac JM, James E. Switch over from intravenous to oral therapy: A concise overview. Journal of pharmacology pharmacotherapeutics. 2014;5(2):83.

69. Banko H, Goldwater SH, Adams E. Smoothing the path for intravenous (IV) to oral (PO) conversion: Where have we come in 11 years? Hospital Pharmacy. 2009;44(11):959-67.

70. Shrayteh ZM, Rahal MK, Malaeb DN. Practice of switch from intravenous to oral antibiotics. Springerplus. 2014;3:717.

71. Sze WT, Kong MC. Impact of printed antimicrobial stewardship recommendations on early intravenous to oral antibiotics switch practice in district hospitals. Pharmacy practice. 2018;16(2):855.

72. Versporten A, Bielicki J, Drapier N, Sharland M, Goossens H. The Worldwide Antibiotic Resistance and Prescribing in European Children (ARPEC) point prevalence survey: developing hospital-quality indicators of antibiotic prescribing for children. J Antimicrob Chemother. 2016;71(4):1106-17.

73. Berild D, Mohseni A, Diep LM, Jensenius M, Ringertz SHJJoac. Adjustment of antibiotic treatment according to the results of blood cultures leads to decreased antibiotic use and costs. 2006, 57(2):326-330.

74. Stevenson KB, Balada-Llasat J-M, Bauer K, Deutscher M, Goff D, Lustberg M, Pancholi P, Reed E, Smeenk D, Taylor $\mathrm{J}$ : The economics of antimicrobial stewardship: the current state of the art and applying the business case model. infection control \& hospital epidemiology 2012, 33(4):389-397.

75. Cameron A, Mantel-Teeuwisse AK, Leufkens HG, Laing RO. Switching from originator brand medicines to generic equivalents in selected developing countries: how much could be saved? Value in health. 2012;15(5):664-73.

76. Simoens S. A review of generic medicine pricing in Europe. GaBI Journal. 2012;1(1):8-12.

77. Godman B, Hill A, Simoens S, Kurdi A, Gulbinovič J, Martin A, Timoney A, Gotham D, Wale J, Bochenek T. Pricing of oral generic cancer medicines in 25 European countries; findings and implications. Generics and Biosimilars Initiative journal 2019.

78. Woerkom Mv, Piepenbrink H, Godman B, Metz Jd, Campbell S, Bennie M, Eimers M, Gustafsson LL. Ongoing measures to enhance the efficiency of prescribing of proton pump inhibitors and statins in The Netherlands: influence and future implications. Journal of comparative effectiveness research. 2012;1(6):527-38.

79. Das N, Khan A, Badini Z, Baloch H, Parkash J. Prescribing practices of consultants at Karachi, Pakistan. JOURNAL-PAKISTAN MEDICAL ASSOCIATION. 2001;51(2):74-7.

80. NaJrni M: H afiz RA, Khan I et al. Prescribing practices: an overview of three teaching hospitals in Pakistan. Pak $J$ Med Res 1997, 36:172-177.

81. Organization $\mathrm{WH}$ : Consultative meeting planning for the global patient safety challenge: medication safety, 19-20 April 2016, WHO Headquarters Geneva, Switzerland: meeting report. In.: World Health Organization; 2016. 
82. Das N, Khan A. Prescribing pattern of consultants and general practitioners in Hyderabad, Pakistan. JCPSP. 1996;6:287-9.

83. Jamshed SQ, Ibrahim MIM, Hassali MAA, Masood I, Low BY, Shafie AA. Perception and attitude of general practitioners regarding generic medicines in Karachi, Pakistan: a questionnaire based study. Southern med review. 2012;5(1):22.

84. Babar A, Khan B, Godman B, Hussain S, Mahmood S, Aqeel T. Assessment of active pharmaceutical ingredients in drug registration procedures in Pakistan: implications for the future. Generics Biosimilars Initiative Journal. 2016;5(4):156-63.

85. McGinn D, Godman B, Lonsdale J, Way R, Wettermark B, Haycox A. Initiatives to enhance the quality and efficiency of statin and PPI prescribing in the UK: impact and implications. Expert Rev PharmacoEcon Outcomes Res. 2010;10(1):73-85.

86. Godman B, Bishop I, Finlayson AE, Campbell S, Kwon HY, Bennie M. Reforms and initiatives in Scotland in recent years to encourage the prescribing of generic drugs, their influence and implications for other countries. Expert Rev PharmacoEcon Outcomes Res. 2013;13(4):469-82.

87. Niranjan V, Malini A. Antimicrobial resistance pattern in Escherichia coli causing urinary tract infection among inpatients. Indian J Med Res. 2014;139(6):945.

88. Gales AC, Castanheira M, Jones RN, Sader HS. Antimicrobial resistance among gram-negative bacilli isolated from Latin America: results from SENTRY Antimicrobial Surveillance Program (Latin America, 2008-2010). Diagn Microbiol Infect Dis. 2012;73(4):354-60.

89. Mir F, Rashid A, Farooq M, Irfan M, ljaz A. Antibiotic sensitivity patterns of staphylococcal skin infections. Journal of Pakistan Association of Dermatology. 2016;25(1):12-7.

\section{Figures}

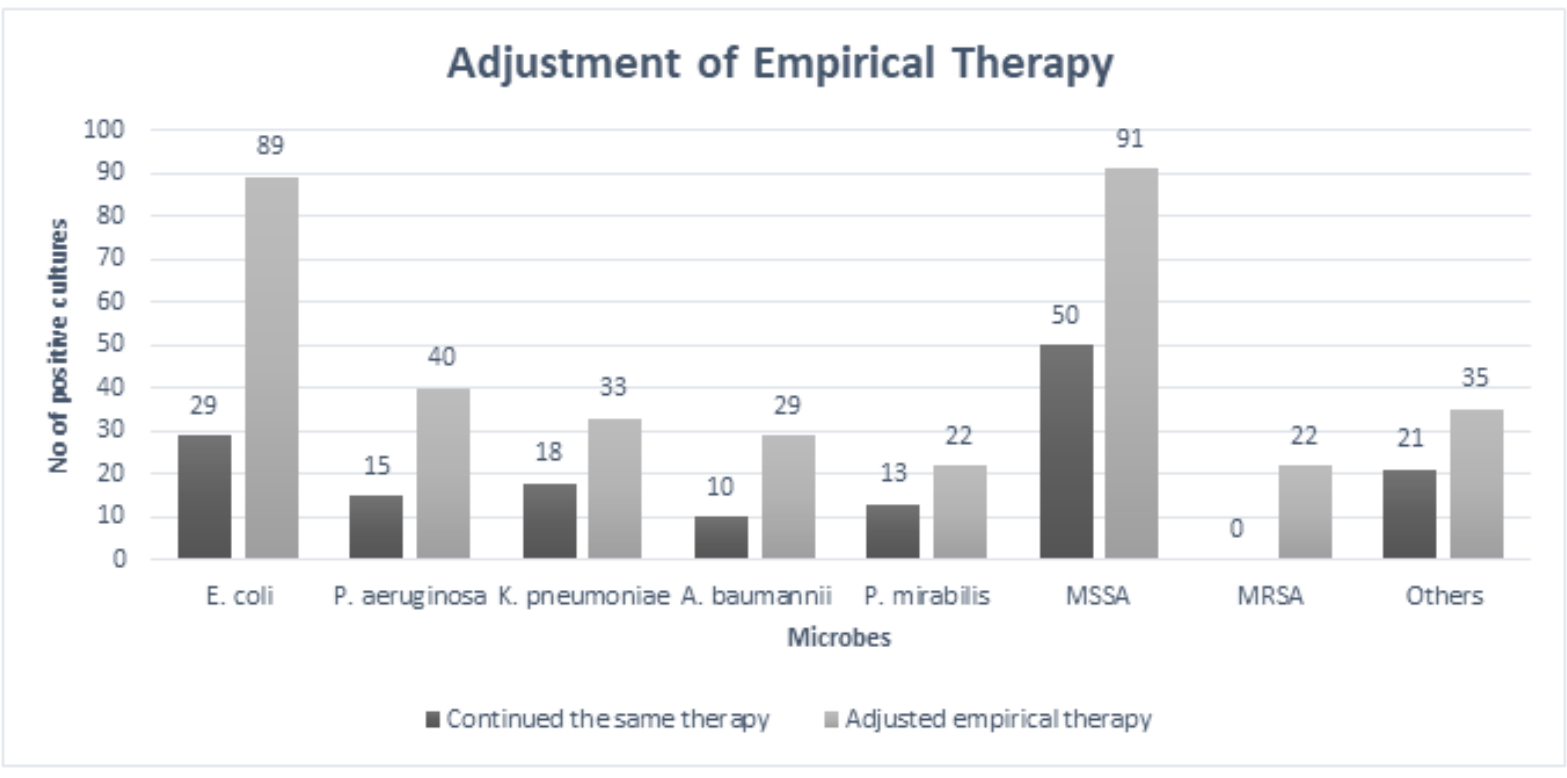

\section{Figure 1}

Adjustment of empirical therapy after the availability of culture sensitivity reports E. coli= Escherichia coli, P. aeruginosa $=$ Pseudomonas aeruginosa, $\mathrm{K}$. pneumoniae $=$ Klebsiella pneumoniae, $\mathrm{A}$. baumannii $=$ Acinetobacter baumannii, P. mirabilis = Proteus mirabilis, MSSA= Methicillin-sensitive staphylococcus aureus, MRSA= Methicillin- 
resistant staphylococcus aureus, Others= Citrobacter, Enterobacter, Salmonella typhi, Serratia marcescens, Streptococcus pyogenes, Staphylococcus epidermidis, Enterococcus faecalis, Staphylococcus saprophyticus 